\title{
Narrativa y género: El camino de la Heroína El arquetipo femenino universal para un nuevo paradigma Proyecto de Investigación $\mathrm{N}^{\circ} 14.4$ Equipo de Investigación ${ }^{(1)}$ Gabriel Los Santos y Tomás Stiegwardt por Columbia College Chicago (EEUU)
} por Facultad de Diseño y Comunicación, Universidad de Palermo (ARG) Marcelo Sabatés, Gabriela Díaz de Sabatés y Carolina Posse Emiliani

\begin{abstract}
Resumen: El Proyecto de Investigación 14.4 presenta y explora algunos de los modelos teóricos y aplicaciones concretas que reformulan el rol y los atributos de la "heroicidad" en diferentes narrativas, estableciendo el Periplo de la Heroina. Pretende crear una brecha dentro del pensamiento tradicional dominante a través del desarrollo de un mapa original para la reflexión en el territorio de la narrativa, con la intención de descubrir nuevas propuestas de roles de género que abran la posibilidad de generar un mundo más rico, complejo e igualitario. La idea de un pensamiento único y hegemónico ya no tiene cabida en el mundo contemporáneo, donde la mirada desde la perspectiva de la diversidad de género ha producido un resquebrajamiento necesario y sanador y ha generado una sociedad más abierta.
\end{abstract}

Palabras clave: Heroicidad - Periplo - Sociedad - Narrativas - Género - Diversidad

[Resúmenes en inglés y portugués en la página 178]

${ }^{(1)}$ Los CVs del Equipo de Investigación pueden consultarse en el Capítulo Directores de Líneas y Coordinadores de Proyectos de esta misma Edición.

\section{Acerca del Proyecto 14.4}

Narrativa y género: El camino de la Heroína

El arquetipo femenino universal para un nuevo paradigma

El Proyecto 14.4 Narrativa y género: El camino de la Heroína. El arquetipo femenino universal para un nuevo paradigma, pretende crear una ruptura dentro del pensamiento 
tradicional dominante en los relatos y desarrolla un mapa original para la reflexión en el territorio de la narrativa, rumbo al descubrimiento de nuevas propuestas de roles de género que abran la posibilidad de forjar un mundo nuevo, más complejo e igualitario.

Se acordó entre la Universidad de Palermo y Columbia College Chicago (EEUU) avanzar en una investigación en la que participan académicos de ambas Instituciones, con la coordinación compartida de Gabriel Los Santos y Tomás Stiegwardt (UP), Marcelo Sabatés, Gabriela Díaz de Sabatés y Carolina Posse Emiliani (Columbia College Chicago, EEUU), con el fin de generar un análisis de un corpus de guiones, imágenes fotográficas, fílmicas, de historietas / comics de la comunicación que permitan abordar la intersección estereotipo/sociedad en relación con su contexto de producción. Los guiones y las imágenes proponen narrativas cuyos productos culturales toman elementos del universo simbólico que los rodea, constituyéndose como constructores y reproductores de imaginarios sociales. Las reflexiones y los resultados obtenidos en el Proyecto 14.4 Proyecto Narrativa y Género, se continúa desarrollando en el Proyecto 14.6 El camino de la Heroína: narrativa, género y diversidad, en marco de la misma Línea de Investigación y bajo la misma Directora Zulema Marzorati (UP).

Sus principales objetivos son:

- Abordar la intersección narrativa/sociedad en relación con su contexto de producción.

- Explorar como productos culturales que toman elementos del universo simbólico, como constructores y reproductores de imaginarios sociales.

- Explorar las producciones y sus estereotipos que desafían a las categorías paradigmáticas contemporáneas.

\section{Acerca de la Línea 14}

Cine e Historia: Reflexiones sobre la imagen política en el cine contemporáneo dirigida por Zulema Marzorati y Mercedes Pombo se desarrolla de manera ininterrumpida desde 2015 en la Facultad de Diseño y Comunicación (UP, Argentina), e incluye hasta el momento seis proyectos finalizados el 14.1 Cine e Historia: Reflexiones sobre la imagen política en el cine contemporáneo, el 14.2 Migraciones y nuevos modos de pensar en la identidad contemporánea ambos coordinados por Zulema Marzorati (UP) y Mercedes Pombo (UP); el 14.3 Cine, memoria y género, una perspectiva en crecimiento coordinado por Zulema Marzorati y Mercedes Pombo (UP) y Claudia Bossay (Universidad de Chile, Chile); el 14.4 Narrativa y Género: El camino de la Heroína, el arquetipo femenino universal para un nuevo paradigma, coordinado por Gabriel Los Santos y Tomás Stiegwardt (UP) y Marcelo Sabatés, Gabriela Díaz de Sabatés y Carolina Posse Emiliani (Columbia College Chicago, EEUU); el 14.5 Violencia física y simbólica. Algunas reflexiones desde el audiovisual y sus discursos coordinado por Zulema Marzorati y Mercedes Pombo (UP), y Alejandra Rodríguez (Universidad Nacional de Quilmes, Argentina); y el 14.6 El camino 
de la Heroína: narrativa, género y diversidad, coordinado por Gabriel Los Santos y Tomás Stiegwardt (UP) y Marcelo Sabatés, Gabriela Díaz de Sabatés y Carolina Posse Emiliani (Consulate General of Argentina in Chicago, EEUU).

\section{Mapa de Áreas y Proyectos}

El Proyecto 14.4 se vincula con todas carreras de grado y posgrado, dado que impacta en la incorporación de la investigación en la lógica de la docencia universitaria, y en la actualización de los contenidos y competencias de la de las carreras de la Facultad, particularmente en las de posgrado: Maestría en Gestión del Diseño y Doctorado en Diseño. Específicamente guarda relación con las carreras que tienen que ver con la imagen: Dirección de Actores de Cine y TV, Dirección de Arte de Cine y TV, Guión de Cine y TV, Licenciatura en Comunicación Audiovisual, Licenciatura en Dirección Cinematográfica, Licenciatura en Fotografía, Licenciatura en Televisión y Producción de Televisión.

\section{Productos y Resultados}

\section{a)- Publicaciones}

Cuaderno del Centro de Estudios de Diseño y Comunicación No91. (2019) Proyecto narrativa y género: El camino de la Heroína. El arquetipo femenino universal para un nuevo paradigma. Coordinación Gabriel Los Santos, Tomás Stiegwardt, Gabriela Díaz de Sabatés y Carolina Posse Emiliani. Año XXII, Julio 2019, Buenos Aires, Argentina. ISSN: 1668-0227. Esta publicación documenta y comunica los resultados alcanzados en el proyecto de investigación 14.4 Narrativa y género. El camino de la Heroína: el arquetipo femenino universal para un nuevo paradigma, y a continuación se detallan los autores y artículos contenidos en ella:

Los Santos Gabriel, Stiegwardt Tomás, Díaz de Sabatés Gabriela y Posse Carolina Emiliani Tomás Stiegwardt (2019) Prólogo (Pp. 13 a 20)

Sabatés Marcelo (2019) Prefacio (Pp. 21 a 23)

Los Santos Gabriel y Stiegwardt Tomás (2019) El camino de la Heroína, el arquetipo femenino universal para un nuevo paradigma (Pp. 25 a 45)

Niedermaier Alejandra (2019) La fotonovela: un camino posible para los desafíos de un nuevo modelo de mujer (Pp. 47 a 63)

Olaizola Andrés (2019) Las heroínas transmediales de Alba Cromm, de Vicente Luis Mora, y La muerte me da, de Cristina Rivera Garza (Pp. 65 a 78)

Vallazza Eleonora (2019) Mujeres pioneras en el cine experimental y el video arte argentino (Pp. 79 a 91)

Saxe Facundo (2019) Heroínas feministas en la historieta. Género, memoria y disidencia sexual en Dora de Minaverry (Pp. 93 a 108)

Mendoz Marina (2019) El Movimiento de Mujeres Indígenas por el Buen Vivir. Intersticios de una lucha feminista, antiextractivista y por la Plurinacionalidad (Pp. 109 a 129) 
Gruber Mónica (2019) Heroínas y malvadas: la construcción de la imagen femenina en Penny Dreadfull (2014-2016), de John Logan (Pp. 131 a 145)

Chalkho Rosa (2019) Las figuras femeninas y su representación musical en la película Safo, historia de una pasión (1943) (Pp. 147 a 166)

Müller Sara (2019) Elizaveta, Leni y Agnès: tres mujeres que cambiaron el cine (Pp. 167 a 184)

Callis Cari (2019) The Spiriting Away of Chihiro: Miyazaki’s Global Heroine (Pp. 185 a 198)

Díaz de Sabatés Gabriela (2019) Gender, activism and social change: Reframing the contemporary heroine (Pp. 199 a 209)

Esterrich Carmelo (2019) Maternidades 'heroicas' en Roma, de Alfonso Cuarón (Pp. 211 a 218)

Kapila Gitanjali (2019) Stuck in a Labyrinth (or a Tower) with the Minotaur and trying to get out: Princess Aurora and Imperator Furiosa as the heroes of the Multimyth (Pp. 219 a 234)

Mueller Rose Anna (2019) The Heroine's Path. Teresa de la Parra: Charting the Path of Latin American Heroines (Pp. 235 a 247)

Steiff Josef (2019) To Lose My Mind And Find My Soul.1 The Masculine and Feminine in Films Set in the Forest (Pp. 249 a 258)

Yates Michelle y Kerns Susan (2019) Destabilizing Journeys: The Chicago Feminist Film Festival and The Fits (Pp. 259 a 265)

\section{b)- Congresos / Coloquios / Plenarios}

IV Coloquio de Investigación y Desarrollo en Diseño Latino. Universidad de Palermo, 29 de julio de 2019. X Congreso Latinoamericano de Enseñanza del Diseño. Semana Internacional del Diseño en Palermo. Se presentó la Línea de Investigación No¹4: Cine y sociedad y sus proyectos, en dos comisiones paralelas, en las que se presentaron los Cuadernos 95 y 91 de la Línea respectivamente:

En la comisión coordinada por Gabriel Los Santos - Tomás Stiegwardt (UP) y Gabriela Díaz de Sabatés - Carolina Posse Emiliani (Columbia College) se expusieron las reflexiones y conclusiones del proyecto 14.4 Narrativa y género, pertenecientes al Cuaderno 91 Narrativa y género: El camino de la Heroína - El arquetipo femenino universal para un nuevo paradigma, que se desarrolla junto al Columbia College Chicago, EEUU. Se reflexionó acerca de los modelos teóricos que reformulen el rol y los atributos de la "heroicidad" en la narrativa, estableciendo El camino de la Heroína: la propuesta crea una ruptura dentro del pensamiento tradicional dominante en los relatos y desarrolla un mapa original para la reflexión en el territorio de la narrativa, rumbo al descubrimiento de nuevas propuestas de roles de género que abran la posibilidad de forjar un mundo nuevo, más complejo e igualitario. Expusieron: Gabriel Los Santos, Tomás Stiegwardt, Gabriela Díaz de Sabatés, Gitanjali Kapila, Carmelo Esterrich, Andrés Olaizola, Eleonora Vallazza, Facundo Saxe, Mónica Gruber y María Sara Mùller. A continuación se detallan las ponencias presentadas en esta Comisión coordinada por Gabriel Los Santos - Tomás Stiegwardt (UP) y Gabriela Díaz de Sabatés - Carolina Posse Emiliani (Columbia College): 
Gabriel Los Santos y Tomás Stiegwardt (Argentina)

El camino de la Heroína, el arquetipo femenino universal para un nuevo paradigma Gitanjali Kapila (EEUU)

Stuck in a Labyrinth (or a Tower) with the Minotaur and trying to get out: Princess Aurora and Imperator Furiosa as the heroes of the Multimyth

Gabriela Díaz de Sabatés (EEUU)

Género, activismo y cambio social: Re encuadrando a la heroína contemporánea.

Carmelo Esterrich (EEUU)

Maternidades 'heroicas' en Roma, de Alfonso Cuarón

Andrés Olaizola (Argentina)

Las heroínas transmediales de Alba Cromm, de Vicente Luis Mora, y La muerte me da, de Cristina Rivera Garza

Eleonora Vallazza (Argentina)

Mujeres pioneras en el cine experimental y el video arte argentino

Facundo Saxe (Argentina)

Historieta, sexo-género y memoria: Dora de Minaverry como archivo feminista sexodisidente

Mónica Gruber (Argentina)

Heroinas y malvadas: la construcción de la imagen femenina en Penny Dreadfull (2014-2016), de John Logan

Rosa Chalko (Argentina)

Las figuras femeninas y su representación musical en la película Safo, historia de una pasión (1943)

María Sara Mùller (Argentina)

Elizaveta, Leni y Agnès: Tres mujeres que cambiaron el cine

$2^{\circ}$ Plenario de Directores de Investigación DC, 27 de agosto y 4 de septiembre - 2018. Es este segundo plenario los Directores de las Líneas y Proyectos de Investigación presentaron a sus pares y al conjunto del Programa de Investigación de la Facultad de Diseño y Comunicación, los resultados obtenidos y/o en proceso (publicaciones y acuerdos), junto con los avances de Proyectos.

La Directora de la Línea de Investigación №14 expuso las conclusiones del Proyecto 14.2 Migraciones y nuevos modos de pensar en la identidad contemporánea (finalizado) y su producto el Cuaderno No77 de reciente publicación, y la apertura del Proyecto 14.3 Cine, memoria y género, una perspectiva en crecimiento.

\section{c)- Formación de Posgrado e Impacto curricular}

La Directora Zulema Marzorati es Docente de Posgrado en Diseño de la Facultad de Diseño y Comunicación en Maestría en Gestión del Diseño y Doctorado en Diseño, y al igual que los Coordinadores Gabriel Los Santos y Tomás Stiegwardt (UP), Marcelo Sabatés, Gabriela Díaz de Sabatés y Carolina Posse Emiliani (Columbia College Chicago, EEUU) incorporan los contenidos de su investigación a sus asignaturas. 


\begin{abstract}
Research Project 14.4 presents and explores some of the theoretical models and concrete applications that reformulate the role and attributes of "heroism" in different narratives, establishing the Heroine Journey. It aims to create a gap within the dominant traditional thought through the development of an original map for reflection in the territory of the narrative, with the intention of discovering new proposals for gender roles that open the possibility of generating a richer, more complex world and egalitarian. The idea of a unique and hegemonic thought no longer has a place in the contemporary world, where the view from the perspective of gender diversity has produced a necessary and healing breakdown and has generated a more open society.
\end{abstract}

Keywords: Heroicity - Periplo - Society - Narratives - Gender - Diversity

Resumo: O Projeto de Pesquisa 14.4 apresenta e explora alguns dos modelos teóricos e aplicações concretas que reformulam o papel e os atributos do "heroísmo" em diferentes narrativas, estabelecendo a Jornada da Heroína. Visa criar um distanciamento no pensamento tradicional dominante através do desenvolvimento de um mapa original para reflexão no território da narrativa, com o intuito de descobrir novas propostas de papéis de gênero que abram a possibilidade de gerar um mundo mais rico, complexo e igualitário. A ideia de um pensamento único e hegemônico não tem mais lugar no mundo contemporâneo, onde a visão na perspectiva da diversidade de gênero produziu uma ruptura necessária e curativa e gerou uma sociedade mais aberta.

Palavras chave: Heroicidade - Periplo - Sociedade - Narrativas - Gênero - Diversidade

[Las traducciones de los resúmenes fueron realizadas a través de traductor automático] 